\title{
Transformer Incipient fault prediction using Support Vector Machine (SVM)
}

\author{
* A. Kumar ${ }^{1}$, Vidya H. A. ${ }^{2}$ \\ ${ }^{l}$ Visvesvaraya Technological University, Belagavi, ${ }^{1}$ kumarbnmiteee@gmail.com \\ ${ }^{2}$ Amrita Vishwa Vidyapeetham, Bengaluru, \\ ㄴkumarbnmiteee@gmail.com, 2 ha_vidya@blr.amrita.edu
}

DOI: $10.51201 /$ JUSST/21/05208

http://doi.org/10.51201/JUSST/21/05208

\begin{abstract}
Power transformer is an important link in power system. Utilities will face a huge loss if a fault occurs transformer. The outage can cause loss to industry sector. Transformer incipient fault can be predicted using Dissolved Gas Analysis (DGA) based on gas ratios. The current work is an effort to use SVM to predict transformer incipient fault more precisely. DGA data of various transformer oil samples were collected and analyzed to select the best SVM kernel function and kernel factor to be used and to observe the prediction accuracy.
\end{abstract}

Key words: DGA, Transformer Incipient fault, IEC 60599, SVM classifier.

\section{Introduction}

Transformers form a crucial link in power system. It is one of the major asset of utilities. With increased demand for electric energy, transformers are being overloaded to cope with the demand. Failure of a transformer in-service, can result in loss of millions of dollars, based on the duration the transformer is out of duty. It is time consuming and costly to replace faulty transformers. Hence it is important to monitor the gases in the transformer condition. Due to various operating conditions in the transformer gasses are evolved in the transformer oil. These gases dissolve in insulation oil and can be used as indicator of incipient fault. Key gases evolved during the operation of transformer are shown in table 1.

Table 1: Key gases evolved during fault

\begin{tabular}{|l|c|l|}
\hline \multicolumn{1}{|c|}{ Key Gas } & $\begin{array}{c}\text { Chemical } \\
\text { representation }\end{array}$ & \multicolumn{1}{c|}{ Fault type } \\
\hline Hydrogen & $\mathrm{H}_{2}$ & Corona \\
\hline $\begin{array}{l}\text { Carbon monoxide and } \\
\text { carbon dioxide }\end{array}$ & $\mathrm{CO} / \mathrm{CO}_{2}$ & $\begin{array}{l}\text { Cellulose insulation } \\
\text { breakdown }\end{array}$ \\
\hline Methane and Ethane & $\mathrm{CH}_{4} / \mathrm{C}_{2} \mathrm{H}_{6}$ & $\begin{array}{l}\text { Low temperature oil } \\
\text { breakdown }\end{array}$ \\
\hline Acetylene & $\mathrm{C}_{2} \mathrm{H}_{2}$ & Arcing \\
\hline Ethylene & $\mathrm{C}_{2} \mathrm{H}_{4}$ & $\begin{array}{l}\text { High temperature oil } \\
\text { breakdown }\end{array}$ \\
\hline
\end{tabular}

Monitoring gases evolved in the transformer oil can help in predicting the possible faults and this can be achieved by using DGA.

\section{Dissolved Gas Analysis and IEC 60599}

One of the most acceptable method to identify incipient fault in transformer is DGA [1]. The combustible concentration limits vary between different countries, continents and

* Corresponding author - A.Kumar 
transformers. Hence setting the concentration limits is not easier. The incipient faults in oil-filled power transformer can be detected using DGA, which is more reliable. DGA is not science, but an art. It is the most prominent test in determining the state of a transformer. It acts as a first indicator to identify partial discharge, deteriorating insulation \& oil, over heating hot spots, and arcing [2]. IEC60599 and IEEEC 57-104TM standards are used as standard for DGA. It helps in early diagnosis and provides opportunity to find suitable cure [3]. A characteristic amount of gas is produced in the transformer oil based on type of fault. There is a significant increase in the individual gas concentration, Total Dissolved Combustible Gas (TDCG). Gas chromatography is used to detect the gases as parts per million (ppm). It is used to identify, separate, and quantify mixtures of gases. The key gases found during DGA are hydrogen $\left(\mathrm{H}_{2}\right)$, methane $\left(\mathrm{CH}_{4}\right)$, acetylene $\left(\mathrm{C}_{2} \mathrm{H}_{2}\right)$, ethylene $\left(\mathrm{C}_{2} \mathrm{H}_{4}\right)$, ethane $\left(\mathrm{C}_{2} \mathrm{H}_{6}\right)$, carbon monoxide $(\mathrm{CO})$, and carbon-di-oxide $\left(\mathrm{CO}_{2}\right)$. By using DGA incipient faults in a transformer can be predicted. Certain gases are formed in transformer oil even under normal transformer operational conditions. Therefore, large sampling is required to build concentration norms. The cost of unplanned outages can be reduced by the early detection of such internal faults in transformer. The interpretation of transformer faults using dissolved gases analysis is produced using some techniques that are assumed by Dornenberg, Rogers, Duval triangle and key gases methods. All the techniques mentioned above have its own pro's and con's. All the techniques do not arrive at same conclusion. The accuracy depends upon the expertise of the person handling the analysis. IEC standard 60599 for ratio method of DGA shown in table 2.

Table 2: IEC 60599 for fault prediction based on DGA

\begin{tabular}{|c|c|c|c|c|c|}
\hline & IEC 60599 & $\begin{array}{l}\mathrm{C}_{2} \mathrm{H}_{2} / \\
\mathrm{C}_{2} \mathrm{H}_{4}\end{array}$ & $\begin{array}{l}\mathrm{CH}_{4} / \\
\mathrm{H}_{2}\end{array}$ & $\begin{array}{l}\mathrm{C}_{2} \mathrm{H}_{4} / \\
\mathrm{C}_{2} \mathrm{H}_{5}\end{array}$ & \\
\hline & $\begin{array}{l}\text { Ratios of characteristic } \\
\text { gases } \\
<0.1 \\
0.1-1 \\
1-3 \\
>3 \\
\end{array}$ & $\begin{array}{l}0 \\
1 \\
1 \\
2\end{array}$ & $\begin{array}{l}1 \\
0 \\
2 \\
2\end{array}$ & $\begin{array}{l}0 \\
0 \\
1 \\
2\end{array}$ & \\
\hline $\begin{array}{l}\text { Case } \\
\text { No. }\end{array}$ & Characteristic Fault & & & & Typical examples \\
\hline 0 & No fault & 0 & 0 & 0 & Normal ageing. \\
\hline 1 & $\begin{array}{l}\text { Partial discharges of low } \\
\text { energy density }\end{array}$ & $\begin{array}{c}0 \text { but not } \\
\text { significant }\end{array}$ & 1 & 0 & $\begin{array}{l}\text { Discharges in gas filled cavities } \\
\text { resulting from incomplete } \\
\text { impregnation or super saturation or } \\
\text { cavitations or high humidity. }\end{array}$ \\
\hline 2 & $\begin{array}{l}\text { Partial discharges of low } \\
\text { energy density }\end{array}$ & 1 & 1 & 0 & $\begin{array}{l}\text { All above but leading to tracking or } \\
\text { perforation of solid insulation. }\end{array}$ \\
\hline 3 & Discharge of low energy & $1-2$ & 0 & $1-2$ & $\begin{array}{l}\text { Continuous sparking in oil between } \\
\text { bad connections of different } \\
\text { potential. Breakdown of oil between } \\
\text { solid materials. }\end{array}$ \\
\hline 4 & Discharge of high energy & 1 & 0 & 2 & $\begin{array}{l}\text { Discharges with power follow } \\
\text { through. Arcing breakdown of oil } \\
\text { between windings or coils, or } \\
\text { between seil to earth. Selector } \\
\text { breaking current. }\end{array}$ \\
\hline 5 & $\begin{array}{l}\text { Thermal fault of Low } \\
\text { temperature } \angle 150^{\circ} \mathrm{C}\end{array}$ & 0 & 0 & 1 & $\begin{array}{l}\text { Generalinsulated conductor } \\
\text { overheating. }\end{array}$ \\
\hline 6 & $\begin{array}{l}\text { Thermal fault of Medium } \\
\text { temperature range } \\
150^{\circ} \mathrm{C}-300^{\circ} \mathrm{C}\end{array}$ & 0 & 2 & 0 & $\begin{array}{l}\text { Local overheating of the core due to } \\
\text { concentrations of flux. Increasing hot } \\
\text { spot temperatures, varying from }\end{array}$ \\
\hline 7 & $\begin{array}{l}\text { Thermal fault of Medium } \\
\text { temperature range } \\
300^{\circ} \mathrm{C}-700^{\circ} \mathrm{C}\end{array}$ & 0 & 2 & 1 & $\begin{array}{l}\text { small hot spots in core, overheating } \\
\text { of copper due to eddy currents, bad } \\
\text { cont acts } \text { joints (pyrolitic carbon }\end{array}$ \\
\hline 8 & $\begin{array}{l}\text { Thermal fault of high } \\
\text { temperature }>700^{\circ} \mathrm{C}\end{array}$ & 0 & 2 & 2 & $\begin{array}{l}\text { formation) up to core and tank } \\
\text { circulating currents }\end{array}$ \\
\hline
\end{tabular}




\section{SVM Algorithm}

Support Vector Machine" (SVM) is a supervised machine learning algorithm which is suitable for both classification and regression challenges [4][5]. In the SVM algorithm, a $n$-dimensional space is plotted where $n$ is the number of features in data set. The value of each feature being the value of a particular coordinate. A hyper-plane is determined that differentiates the two classes the classification is done. The hyperplane should divide the set of samples such that all the points with the same label are on the same side of the hyperplane [6]-[11].

\section{MATLAB simulation and analysis}

For the experimentation and testing a data set of 200 samples were used. The data used were concentration of various gases like $\mathrm{C}_{2} \mathrm{H}_{2}, \mathrm{CH}_{4}, \mathrm{C}_{2} \mathrm{H}_{6}, \mathrm{C}_{2} \mathrm{H}_{4}$ and $\mathrm{H}_{2}$. The experimentation was conducted in two stages. In the first investigation various kernel function and kernel factors of SVM was used and predictions were done. The purpose was to identify the model best suited for fault prediction. The second investigation was done by varying the Kernel Scale and observing the impact on the prediction accuracy for the model selected. MATLAB version R2020a was used for the investigation. Table 3 shows sample data.

Table 3: Sample data of gas concentrations in $\mathbf{p p m}$.

\begin{tabular}{|c|c|c|c|c|c|c|}
\hline \multirow{2}{*}{$\begin{array}{l}\text { Sl. } \\
\text { No. }\end{array}$} & \multicolumn{5}{|c|}{ Gas Concentrations ppm } & \multirow{2}{*}{ Fault type } \\
\hline & $\mathbf{H}_{2}$ & $\mathrm{CH}_{4}$ & $\mathbf{C}_{2} \mathbf{H}_{2}$ & $\mathrm{C}_{2} \mathrm{H}_{4}$ & $\mathrm{C}_{2} \mathrm{H}_{6}$ & \\
\hline 1 & 2238 & 826 & 537988 & 335279 & 4008 & High intensity discharge \\
\hline 2 & 2373 & 817 & 669150 & 447061 & 4284 & High intensity discharge \\
\hline 3 & 2394 & 754 & 673175 & 360327 & 4049 & High intensity discharge \\
\hline 4 & 6729 & 323 & 2 & 45353 & 2323 & Low intensity discharge \\
\hline 5 & 10000 & 800 & 40 & 9 & 222 & Low intensity discharge \\
\hline 6 & 9900 & 780 & 35 & 10 & 150 & Low intensity discharge \\
\hline 7 & 10000 & 769 & 36 & 11 & 180 & Low intensity discharge \\
\hline 8 & 30 & 80 & 3 & 220 & 675 & Thermal fault \\
\hline 9 & 4000 & 6076 & 2 & 23232 & 4544 & Thermal fault \\
\hline 10 & 100 & 200 & 1212 & 3222 & 188 & No Fault \\
\hline
\end{tabular}

\section{Results and discussion}

\subsection{Selection of Algorithm}

Based on the kernel function, there are 4 types of SVM algorithm available for fault classification. They are Linear SVM (LSVM), Quadratic SVM (QSVM), Cubic SVM (CSVM) and Fine Gaussian SVM (FGSVM). In the initial experimentation fine tuning of the kernel factor with all the 4 cases was taken up to identify the most suitable kernel function and the value of kernel factor. The results are tabulated in Table 4 and represented in figure 1. 
Table 4: Prediction accuracy for different kernel function and kernel values

\begin{tabular}{|c|c|c|c|c|c|c|c|c|}
\hline $\begin{array}{c}\text { Kernel } \\
\text { Scale }\end{array}$ & $\mathbf{0 . 1}$ & $\mathbf{0 . 2 5}$ & $\mathbf{0 . 4}$ & $\mathbf{0 . 5}$ & $\mathbf{0 . 6}$ & $\mathbf{0 . 7 5}$ & $\mathbf{1}$ & $\mathbf{2}$ \\
\hline LSVM & 84.4 & 69.8 & 61.8 & 59.8 & 60.3 & 60.3 & 70.9 & 84.4 \\
\hline QSVM & 92.0 & 89.9 & 86.9 & 85.4 & 84.9 & 85.4 & 70.9 & 73.4 \\
\hline CSVM & 67.8 & 61.3 & 91.5 & 91.5 & 91.5 & 81.4 & 70.9 & 73.4 \\
\hline FGSVM & 88.4 & 88.9 & 87.9 & 86.9 & 85.9 & 83.9 & 87.9 & 72.9 \\
\hline
\end{tabular}

The results obtained depicted that CSVM gave a consistent prediction efficiency of 91.5\% over a kernel scale of 0.4 to 0.6 . The prediction efficiency of other methods was found to be not at the range of CSVM and was also not consistent. Hence CSVM was selected for the analysis in this work. The kernel scale was fixed at 0.55 . The confusion matrix of CSVM with kernel factor of 0.55 is shown in figure 2.

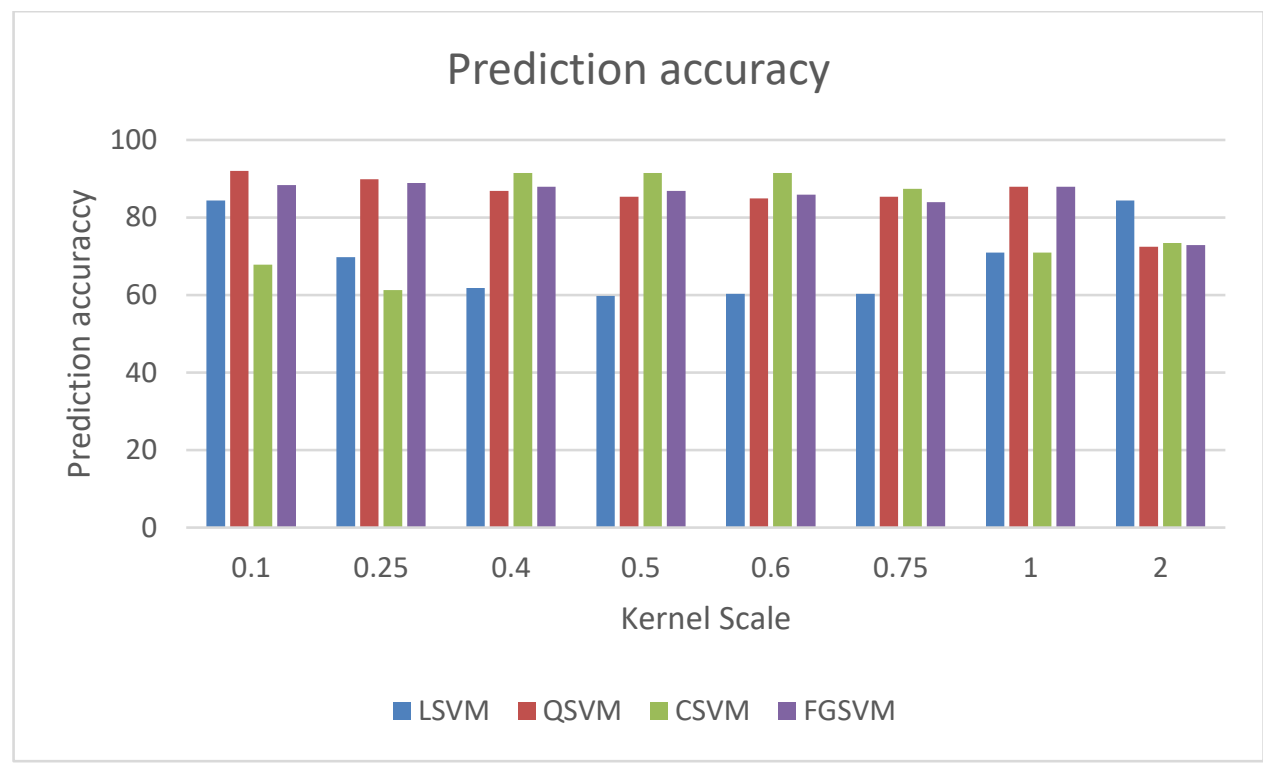

Figure 1: Prediction accuracy of various SVM function with the variation of kernel scale 


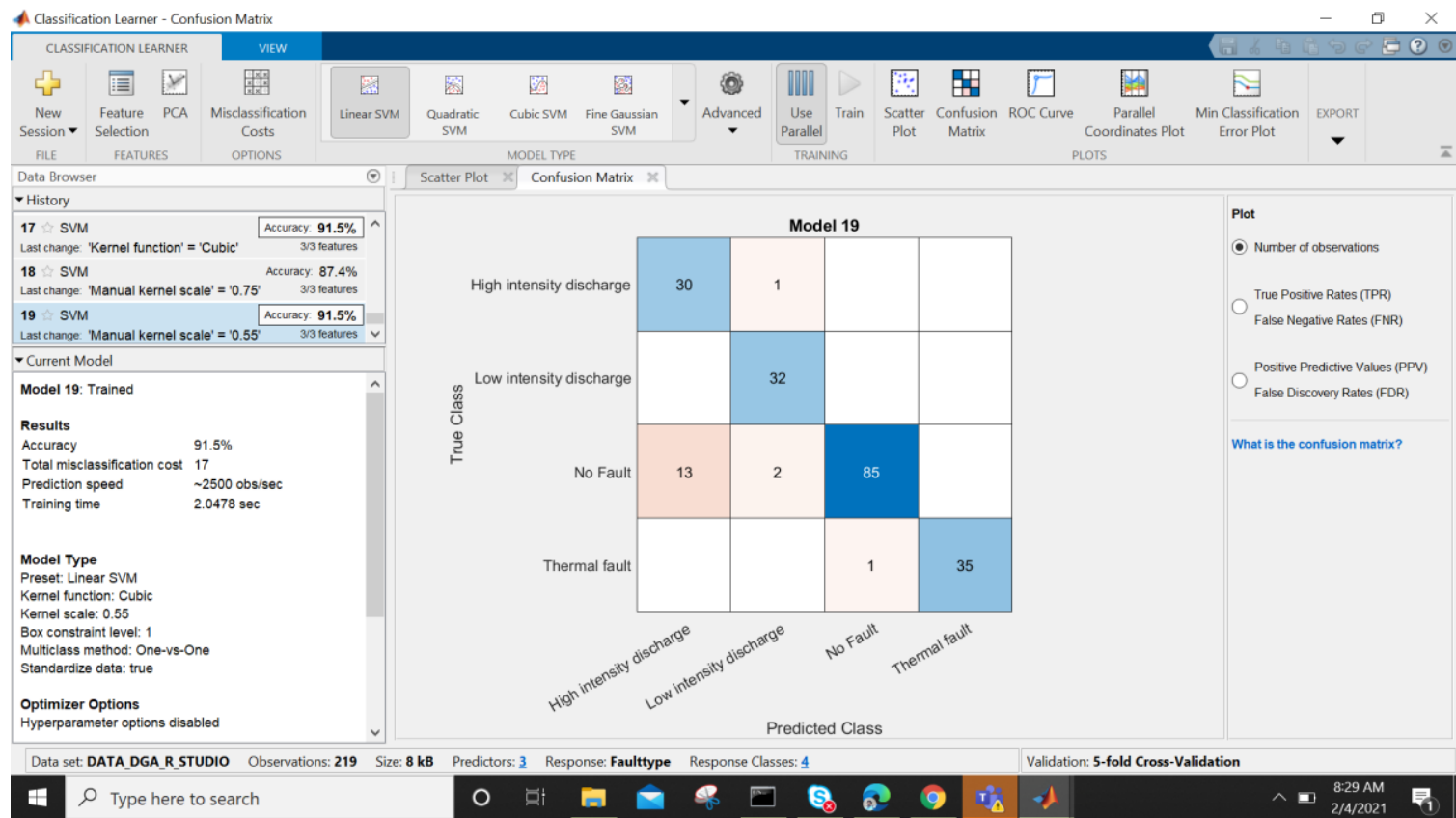

Figure 2: Confusion matrix for CSVM with kernel scale 0.55

The confusion matrix is a matrix of true class versus predicted class. It can be seen from the confusion matrix that the selected model has confusion in the prediction of "NoFault" case only.

\subsection{Transformer incipient fault prediction}

From the analysis carried out in 5.1 the CSVM with kernel scale of 0.55 was selected. Region of Conversion (ROC) was used to identify the prediction accuracy for each of the fault type i.e. Low intensity fault, High intensity fault, Thermal fault and No fault cases. The ROC gives the prediction accuracy as a plot of true positive predictions $\mathrm{v} / \mathrm{s}$ false positive predictions. The area under curve (AUC) is an indicator of accuracy. If the AUC is 0.97 it indicates $97 \%$ accuracy of prediction. The ROC curve for the four classes of faults namely Low intensity fault, High intensity fault, Thermal fault and No-fault cases are shown in figure 3 to figure 6 . 


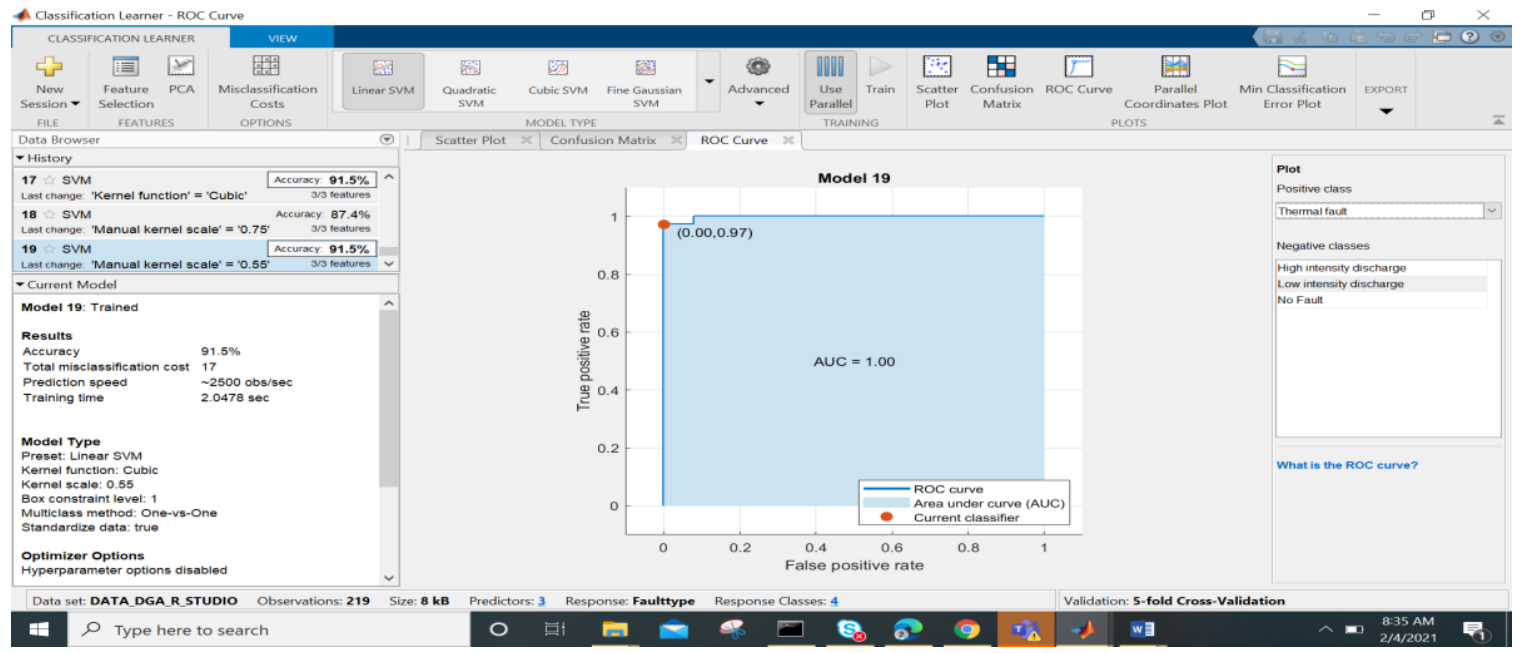

Figure 3: ROC for Thermal fault, $\mathrm{AUC}=1.0$

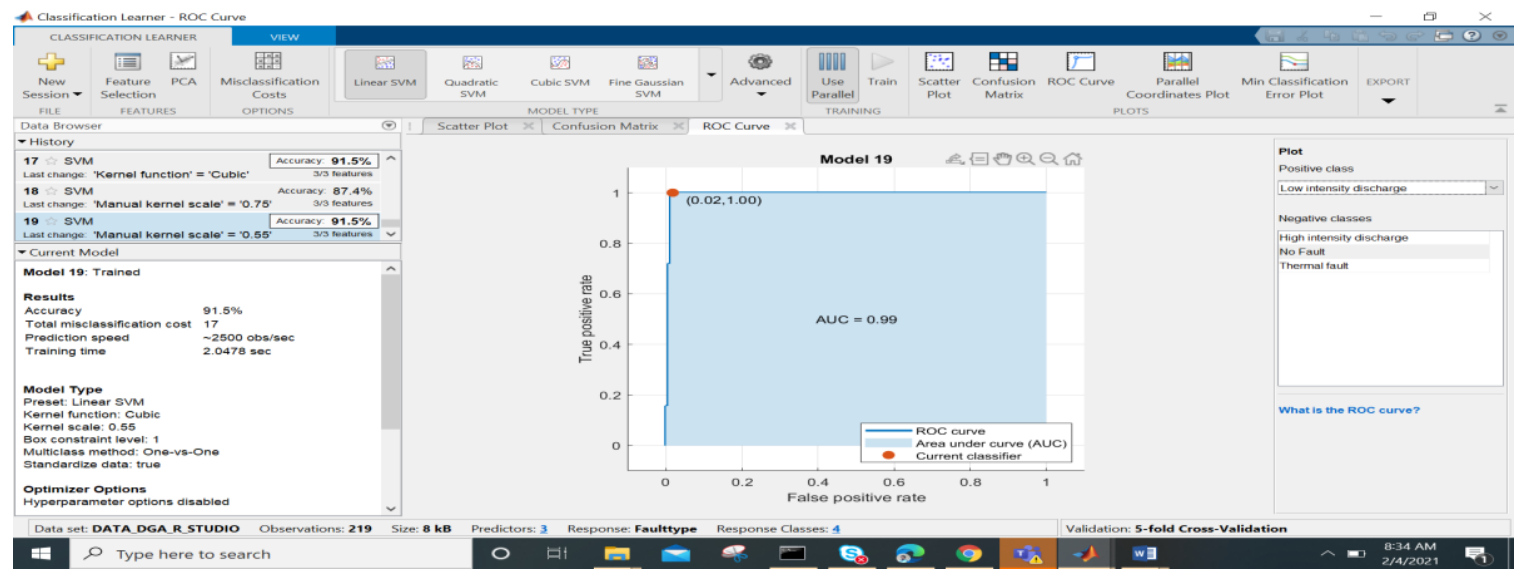

Figure 5: ROC for Low intensity discharge fault, $\mathrm{AUC}=0.99$

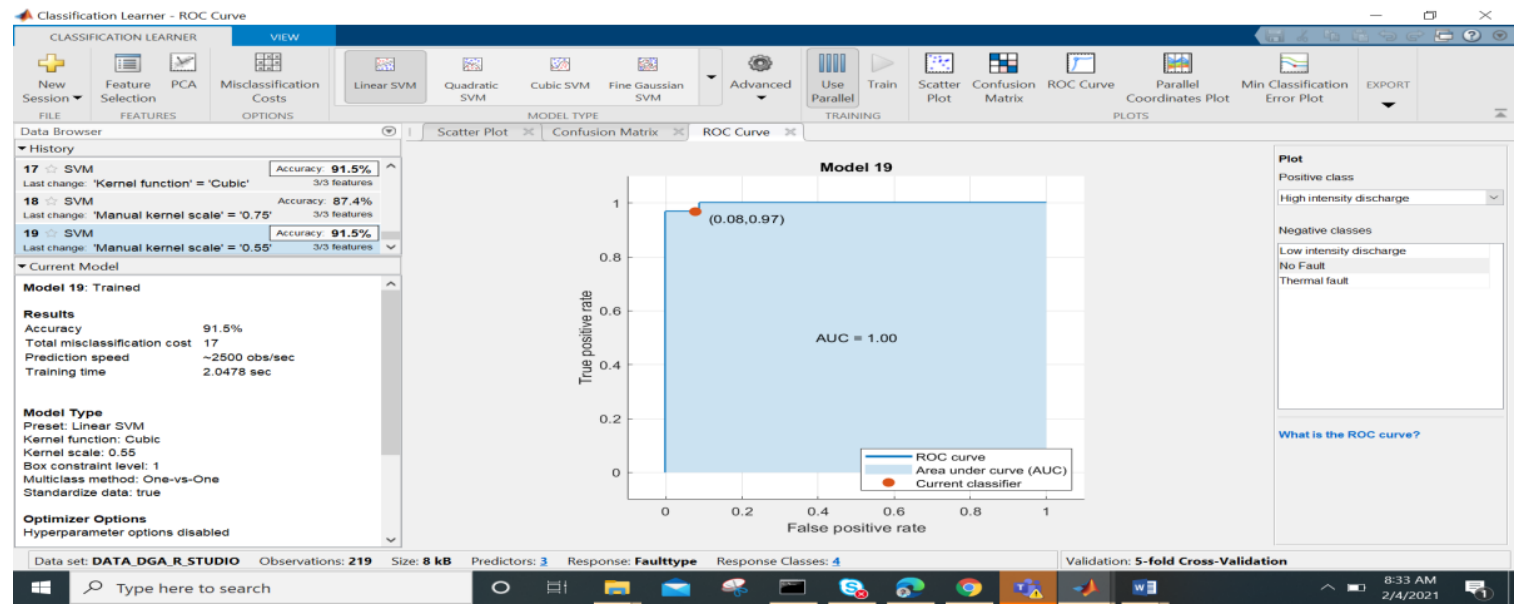

Figure 6: ROC for High intensity discharge fault, $\mathrm{AUC}=0.99$ 


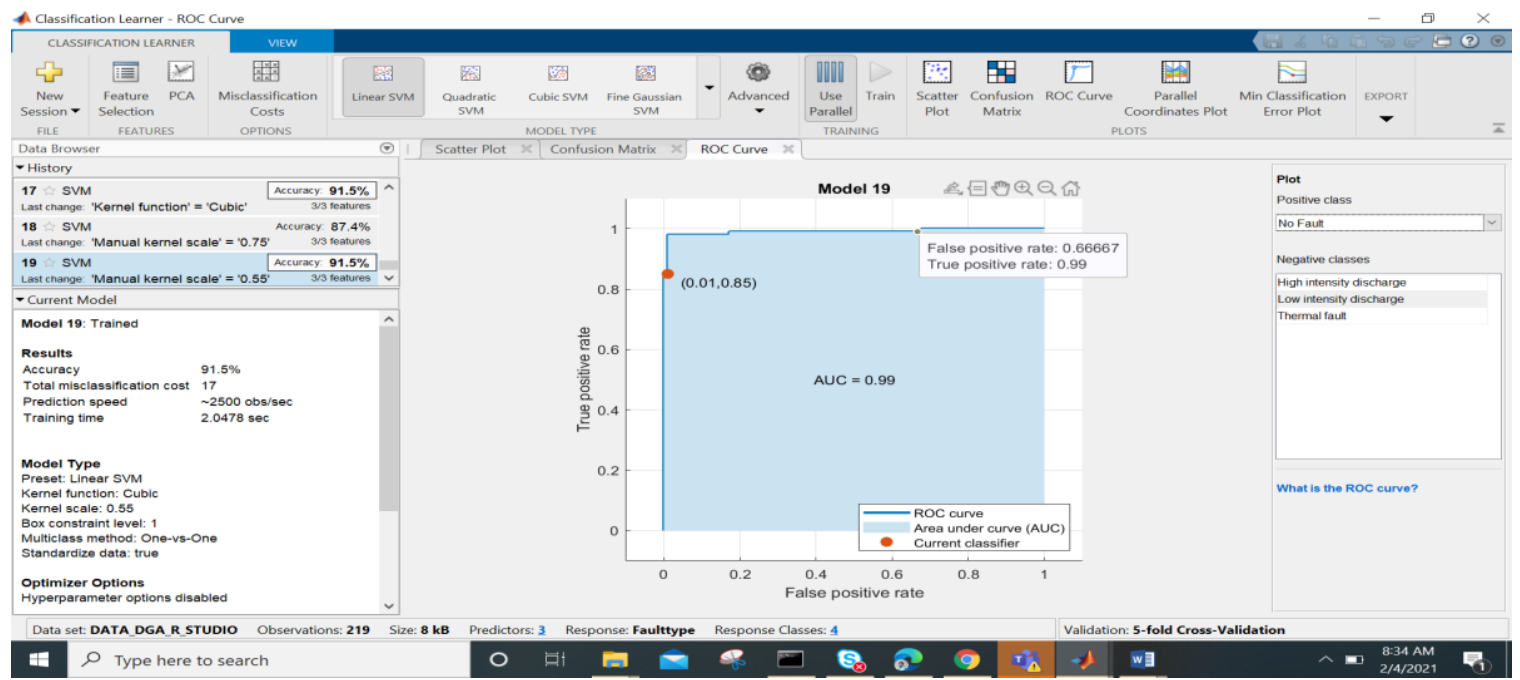

Figure 7: ROC for No-fault, $\mathrm{AUC}=0.99$

The observations are tabulated in table 5

Table 5: Prediction accuracy of incipient faults using CSVM algorithm.

\begin{tabular}{|c|l|c|c|}
\hline Sl. No. & Type of incipient fault & AUC & Prediction accuracy \\
\hline 1 & Thermal fault & 1.0 & $100 \%$ \\
\hline 2 & Low intensity discharge fault & 0.99 & $99 \%$ \\
\hline 3 & High intensity discharge fault & 1.0 & $100 \%$ \\
\hline 4 & No-fault & 0.99 & $99 \%$ \\
\hline
\end{tabular}

\section{Conclusion}

Transformer incipient fault prediction was carried out using SVM machine learning algorithm. It was observed that CSVM model gave better and consistent prediction compared to LSVM, QSVM, and FGSVM. Further the prediction rate is high in CSVM with kernel scale of 0.55 .

\section{Acknowledgement}

The authors wish to thank the management of Amrita School of Engineering, Amrita Vidyapeetam, Bengaluru Campus, GAT \& its R\&D center in Department of EEE and BNMIT \& its R\&D center in Department of EEE for providing opportunity to carry out our research work.

\section{References}

1. M.Wang, A.J.Vandermaar and K.D.Srivastava, "Review of condition assessment of power transformers in service”, vol 18, no.6, IEEE Electrical Insulation Magazine, Nov/Dec 2002.

2. $M N$ Bandyopadhyay, "Condition monitoring for Power transformer", International conference on condition monitoring and diagnosis, 2008.

3. Ahmed Abu-Siada,Sdood Hmood," Fuzzy logic approach for power transformer asset management based on dissolved gas in oil analysis", Chemical Engineering Transactions, Vol 33, 2013. Pp: 997-1002. 
4. Yan Zhang, Bide Zhang, Yuchun Yuan, Zichun Pei, "Transformer Fault Prediction Based on Support Vector Machine”, IEEE, 978-1-4244-6379-7/10.

5. S. Sasank Varthakavi, Babu, D. Rohith Pra, Reddy, L. Kumar Redd, and Remya Ajai A. S., "Analysis of preprocessing algorithms for face detection using KNN and SVM classifiers", in 10th International Conference on Advances in Computing, Control, and Telecommunication Technologies, ACT 2019, 2019.

6. Kavitha K. R., Gopinath, A., and Gopi, M., "Applying Improved SVM Classifier for Leukemia Cancer Classification Using FCBF”, in 2017 International Conference on Advances in Computing, Communications and Informatics (ICACCI), Udupi, India, 2017.

7. M. V. Sukanya, Shiju Sathyadevan, and Sreeveni, U. B. Unmesha, "Benchmarking support vector machines implementation using multiple techniques”, in Advances in Intelligent Systems and Computing, vol. 320, pp. 227-238, 2015.

8. S.M.S. and Maya L. Pai, "Improving the Performance of Sigmoid Kernels in Multiclass SVM Using Optimization Techniques for Agricultural Fertilizer Recommendation System”, International Conference on Soft Computing Systems. Springer, vol. 837, 2018.

9. K.K. Natarajan and Gokulachandran J., "Artificial Neural Network Based Machining Operation Selection for Prismatic Components", International Journal of Advanced Science, Engineering and Information Technology, vol. 10, no. 2, pp. 618-628, 2020.

10. Chaitanya Medini, Asha Vijayan, Ritu Maria Zacharia, Lekshmi Priya Rajagopal, Bipin Nair and Shyam Diwakar, "Spike encoding for pattern recognition: Comparing cerebellum granular layer encoding and BSA algorithms", 2015 International Conference on Advances in Computing, Communications and Informatics (ICACCI), IEEE, 978-1-4799-8792-4/15, 2015.

11. H Haripriya, Prathibhamol Cp , Yashwant RPai, M Sai Sandeep, Arya M Sankar, Srinivas Nag Veerla and Prema Nedungadi, "Multi Label Prediction Using Association Rule Generation and Simple k-Means”, 2016 International Conference on Computational Techniques in Information and Communication Technologies (ICCTICT), IEEE, 978-1-5090-0082-1/16, 2016.

\section{Biographies}

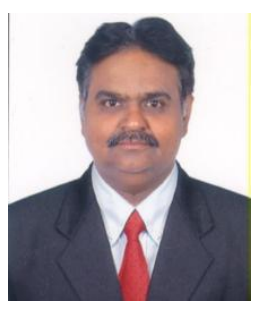

A. Kumar was born in Karnataka, India, in 1969. He obtained the B.E. degree in Electrical and Electronics Engineering from Bangalore University, Karnataka, in 1993, the M.S. degree in Elctronics and controls from BITS, Pilani, in 1999, the M.Sc (Engg) degree in Electrical Sciences from Visvesvaraya Technological University, India, in 2013 respectively. His area of research includes High voltage Engineering and Machine learning.

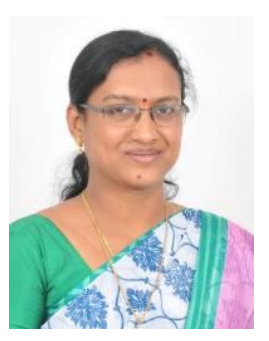

Vidya H.A was born in Karnataka, India in 1974. She obtained the B.E. degree in Electrical and Electronics Engineering from Mysore University, India, in 1996, the M.Tech degree in Computer Application in Industrial Drives from Visvesvaraya Technological University, India, in 2001, and the Ph. D degree in Electrical Sciences from Visvesvaraya Technological University, India, in 2009 respectively. She is a Senior IEEE Member, Fellow Institution of Engineers (FIE), Fellow Indian Society of Lighting Engineers (FISLE), \& life member MISTE

Presently, she is the Professor and Chair, Department of EEE with Amrita School of Engineering, Amrita Vidyapeetam, Bengaluru Campus. India. Her research interests include Power Quality issues in electrical engineering and High voltage engineering. 